Didaché: Journal of Christian Education

Vol. 2, No. 2 (2021): 192-202

e-ISSN: 2722-8584

Published by: Sekolah Tinggi Teologi Simpson Ungaran

DOI: $10.46445 /$ djce.v2i2.432

\title{
Korelasi Model Pembelajaran Kooperatif Tipe TGT dan Motivasi Belajar Pendidikan Agama Kristen
}

\author{
Enri Yana Putri Enos, Tri Supartini, Sarce Rien Hana, Hengki Wijaya \\ Sekolah Tinggi Filsafat Teologi Jaffray Makassar \\ email: bettywija1616@gmail.com
}

\begin{abstract}
The problem in this study is the lack of student motivation in following Christian Religious Education subjects. For this reason, the purpose of this study was to determine the extent of the effect of the cooperative learning model of the team games tournamnet type on the motivation to learn Christian Religious Education in seventh grade students of SMP Negeri 1 Simbuang Tana Toraja. The author uses the method of distributing questionnaires to 20 students in the form of open statements and open interviews to 10 students. The purpose of conducting interviews is to strengthen the results of the questionnaires distributed and direct observations. From the correlation results of data analysis using SPSS, it shows that the team games tournament type cooperative learning model has an effect on students' intrinsic motivation with a significant result, namely 0.671 which is in a strong/high relationship, while the Teams Games Tournament on extrinsic motivation gets a significant result, namely 0.479 which is at moderate/moderate relationship. Students' learning motivation increases both intrinsic motivation and extrinsic motivation. Thus, it can be concluded that the team games tournament type cooperative learning model has an effect on students' learning motivation.
\end{abstract}

Keywords: Cooperative Learning Model, TGT, Motivation, Intrinsic, Extrinsic

\begin{abstract}
Abstrak: Permasalahan dalam penelitian ini adalah kurangnya motivasi belajar siswa dalam mengikuti mata pelajaran Pendidikan Agama Kristen. Untuk itu, tujuan Penelitian ini adalah untuk mengetahui sejauhmana pengaruh model pembelajaran kooperatif tipe teams games tournamnet terhadap motivasi belajar Pendidikan Agama Kristen siswa kelas VII SMP Negeri 1 Simbuang Tana Toraja. Penulis menggunakan metode pembagian angket kepada 20 siswa dalam bentuk pernyataan yang bersifat terbuka dan wawancara terbuka kepada 10 siswa, Tujuan dilakukan wawancara untuk memperkuat hasil dari angket yang dibagikan dan observasi yang dilakukan secara langsung. Dari Hasil korelasi analisa data menggunakan SPSS menunjukkan bahwa model pembelajaran kooperatif tipe Teams Games Tournament berpengaruh terhadap motivasi intrinsik siswa dengan hasil signifikan yaitu 0,671 yang berada pada hubungan kuat/tinggi, sedangkan Teams Games Tournament terhadap motivasi ekstrinsik mendapatkan hasil yang signifikan yaitu 0,479 yang berada pada hubungan cukup/sedang. Motivasi belajar siswa meningkat baik motivasi intrinsik maupun
\end{abstract}


motivasi ekstrinsik. Dengan demikian dapat disimpulkan bahwa model pembelajaran kooperatif tipe Teams Games Tournament berpengaruh terhadap motivasi belajar siswa.

Kata Kunci: Model Pembelajaran Kooperatif, TGT, Motivasi, Intrinsik, Ekstrinsik

Article History $\quad$ Received: July 31, $2021 \quad$ Revised: Dec. 22, $2021 \quad$ Accepted: Dec. 31, 2021

This is an open access article under the CC BY-SA license (c) (i) (2)

\section{Pendahuluan}

Pentingnya Pendidikan Agama Kristen dalam keluarga, pendidikan, bahkan masyarakat agar umat manusia memiliki pengenalan akan Kristus. Sekolah yang merupakan suatu lembaga dalam dunia pendidikan berperan penting untuk mengajarkan PAK agar peserta didik memiliki pemahaman yang benar mengenai Allah, Yesus Kristus, dan Roh Kudus. Beberapa model pembelajaran kooperatif yaitu Team Assisted Individualization (TAI), Student Team Achievement Division (STAD), Jigsaw, Team Game Tournament (TGT), Coperative Integrated Reading and Composition, Learning Together, Structure Dyadic Methods, Group Investigation, dan Complex Instructure (Sumantri, 2016, p. 56) dapat digunakan untuk melengkapi kegiatan pembelajaran PAK. Model pembelajaran kooperatif sangat efektif saat memberikan pembelajaran bagi siswa dalam pengembangan diri dan pembentukan karakter siswa serta melatih siswa untuk menciptakan suatu kreativitas. Dari model pembelajaran di atas, salah satu model yang paling efektif yaitu model pembelajaran tipe Teams Games Tournament (TGT).

Model pembelajaran kooperatif merupakan suatu model pembelajaran yang dilakukan oleh guru kepada siswa dengan membentuk kelompokkelompok kecil sehingga terjadi interaksi dan relasi tiap-tiap anggota kelompok yang bertujuan untuk menciptakan kerja sama, komunikasi yang baik, saling membantu, dan saling memotivasi satu dengan yang lainnya. Pembelajaran kooperatif merupakan model pembelajaran yang para siswa bekerjasama dalam suatu kelompok kecil dengan saling bertukar pikiran, saling menguatkan, dan saling membantu (Edison, 2017, p. 19). Pembelajaran kooperatif adalah suatu model pembelajaran dimana siswa belajar dalam kelompok kecil yang memiliki tingkat kemampuan yang berbeda, sehingga dalam menyelesaikan tugas kelompok, setiap anggota saling kerjasama dan membantu untuk memahami suatu bahan pembelajaran (Ismawati \& Hindarto, 2011, p. 39). 
Teams Games Tournament (TGT) merupakan salah satu tipe model pembelajaran yang membagi siswa dalam beberapa kelompok heterogen yang beranggotakan empat sampai lima orang siswa agar tiap-tiap anggota dalam kelompok dapat berbaur dan penyebaran kemampuan siswa pun merata (Edison, 2017, p. 221). Pembelajaran kooperatif tipe Teams Games Tournament (TGT) lebih membuat siswa bertanggung jawab secara aktif terhadap tugas yang diberikan karena menyenangkan, menantang serta memotivasi siswa untuk berpartisipasi aktif dalam menyelesaikan soal secara kelompok yang di dalamnya terdapat games dan turnamen (Anggraeni \& Wasitohadi, 2014, p. 124). Teams Games Tournament adalah model pembelajaran dengan membentuk kelompok untuk memicu minat belajar siswa sehingga menumbuhkan semangat belajar bagi siswa (Astriana, Murdani, \& Mariyam, 2017, p. 29). Proses pembelajaran juga akan terasa menyenangkan karena kegiatan belajar yang mengandung permainan.

Ada beberapa poin yang menjadi ciri khas dari motivasi intrinsic. Hal-hal tersebut yakni adanya kesadaran dalam diri siswa, adanya keinginan untuk dihargai, pemberian nilai kepada siswa agar siswa dapat melihat dan mengetahui hasil kerjanya, adanya kuriositas dalam diri. Motivasi ekstrinsik yang memicu motivasi murid diantaranya ialah kompetisi atau persaingan, fasilitas belajar yang nyaman dan mendukung proses pembelajaran, dan guru yang memiliki kemampuan mengajar yang baik.

Berdasarkan penjelasan di atas, model pembelajaran yang tepat dapat membantu siswa agar termotivasi dalam belajar PAK ialah Teams Games Tournament, karena tipe tersebut mengandung permainan dan pertandingan yang dilakukan oleh setiap kelompok (Trianto, 2012, p. 83). Permainan dan pertandingan yang dilakukan bukan sekedar hanya untuk bersenang-senang, namun dilakukan untuk menarik perhatian siswa terhadap materi yang disampaikan oleh guru dan memotivasi siswa untuk lebih giat dalam belajar. Adanya permainan dan pertandingan akan memberikan persaingan antar kelompok belajar sehingga membuat setiap siswa harus memahami materi yang telah guru jelaskan. Melalui permainan dan pertandingan ini secara tidak langsung akan memberi motivasi bagi siswa untuk belajar secara pribadi maupun kelompok. Dalam pelajaran PAK siswa memiliki kecenderungan tertentu karena terkadang bersifat monoton. Model pembelajaran melalui permainan dan pertandingan dengan memotivasi belajar siswa pada pelajaran PAK akan membuat siswa secara individu atau kelompok bekerja keras dan 
bekerjasama untuk mendapat hasil yang terbaik. Setiap siswa akan termotivasi untuk belajar karena adanya persaingan antar kelompok. Dalam kelompok belajar yang telah dibagi dalam bentuk heterogen juga dapat membuat siswa termotivasi untuk belajar ketika melihat teman kelompok belajar, dan memberikan motivasi kepada siswa yang kurang dalam belajar, sehingga terjadi kekompakkan dalam kelompok untuk belajar bersama.

Adapun rumusan masalah dalam penelitian ini adalah sejauh mana pengaruh model pembelajaran kooperatif tipe Teams Games Tournament terhadap motivasi belajar Pendidikan Agama Kristen siswa kelas VII di SMPN 1 Simbuang?

\section{Metode}

Metode penelitian yang digunakan oleh penulis adalah jenis penelitian kuantitatif. Penelitian kuantitatif merupakan metode penelitian dengan melakukan pengukuran secara objektif terhadap suatu fenomena dengan menggunakan simbol-simbol dan teknik perhitungan sehingga menghasilkan suatu kesimpulan (Bahri et al., 2021; Jankawatu, 1997, p. 12). Dalam teknik perhitungan ini, penulis mengunakan analisis korelasi. Disamping itu, peneliti memberikan angket kepada dua puluh (20) responden, yaitu siswa kelas VII SMP, serta wawancara kepada sepuluh (10) responden untuk memperkuat hasil angket yang ada, serta penulis juga mengadakan observasi lapangan dengan menganalisis secara langsung masalah yang terjadi dalam kelas dan menerapkan model pembelajaran secara langsung untuk menangani masalah yang terjadi dalam kelas. Jenis penelitian yang digunakan oleh penulis dalam penelitian ini adalah penelitian lapangan yang bersifat kuantitatif yaitu hasil penelitian tindakan kelas dengan menerapkan model pembelajaran kooperatif tipe Teams Games Tournament. Dalam penelitian ini, penulis mengadakan pengukuran variabel dengan menggunakan skala likert, rating skala, dan koefisien korelasi. Dengan menggunakan Skala Likert, maka variabel yang diukur dijabarkan menjadi indikator variabel. Rating skala digunakan untuk mengukur sikap dan juga digunakan untuk mengukur pandangan responden terhadap situasi lingkungan (Sugiyono, 2012, p. 136). Data yang diperoleh juga adalah data kuantitaif (angka) yang kemudian ditafsirkan dalam pengertian kualitatif (Wijaya, 2018, p. 81).

Setelah nilai-nilai yang diperoleh dalam rumus korelasi diketahui, penulis menghitung nilai korelasi dengan membuat tabel sebagai penolong, selanjutnya 
menghitung nilai yang sudah terhitung (Siregar, 2017, p. 196). Berikut adalah rumus yang digunakan oleh penulis:

$$
r_{x y}=\frac{n \Sigma X Y-(\Sigma X)(\Sigma Y)}{\sqrt{\left\{n \Sigma X^{2}-(\Sigma X)^{2}\right\}\left\{n \Sigma Y^{2}-(\Sigma Y)^{2}\right\}}}
$$

$\mathrm{Kd}=\left(\mathrm{r}_{\mathrm{xy}}\right) \times 100 \%$ Koefisien Korelasi

Keterangan (Siregar, 2017, p. 196):

- $\mathrm{r}_{\mathrm{xy}} \quad=$ Koefisien antara variable $\mathrm{X}$ dan $\mathrm{Y}$

- $\mathrm{Kd}=$ Koefesien determinasi variable $\mathrm{X}$ terhadap $\mathrm{Y}$

- $\mathrm{Y} \quad=$ Nilai data variable $\mathrm{X}$

- $\mathrm{n} \quad$ = Banyak anggota sampel pengamatan.

Berikut adalah tabel untuk menentukan kekuatan hubungan antarvariabel (Widiyanto, 2014, p. 228):

Tabel 1. Interprestasi Koefisien Korelasi

\begin{tabular}{cc}
\hline Interval Nilai & Kekuatan Hubungan \\
\hline $0,00-0,199$ & Sangat rendah atau lemah sekali \\
\hline $0,200-0,399$ & Rendah atau lemah \\
\hline $0,400-0,599$ & Sedang atau cukup \\
\hline $0,600-0,799$ & Tinggi atau kuat \\
\hline $0,800-1,000$ & Sangat tinggi atau kuat sekali \\
\hline
\end{tabular}

Langkah-langkah dalam model pembelajaran kooperatif tipe teams games tournament yang diuraikan oleh Slavin adalah sebagai berikut (Tiya, 2017, p. 181):

1. Presentasi Kelas. Presentasi Kelas merupakan proses dalam meembuka kelas dengan memberikan motivasi dan materi pembelajaran kepada siswa. Sebaliknya siswa juga diberikan kesempatan untuk mempresentasikan pendapat masing-masing.

2. Membentuk Kelompok Belajar. Kelompok belajar merupakan kelompok yang terdiri dari 5-6 orang siswa yang berbeda-beda baik ras, suku, maupun tingkat kemampuan berpikir. Kelompok belajar dibentuk agar setiap siswa dapat saling bekerjasama dalam mengerjakan tugas maupun pertanyaan yang diberikan oleh guru.

3. Permainan Akademik. Permainan merupakan alat dalam menyampaikan pesan berupa aktivitas yang memiliki rasa kegembiraan dan saling berinteraksi antar pemain untuk bersaing. Para pemain akan mengikuti setiap peraturan yang berlaku untuk mencapai suatu tujuan tertentu (Sholikah \& Buditjahjanto, 2013, p. 709). 
4. Turnamen. Turnamen merupakan suatu struktur dalam belajar yang di dalamnya terdapat permainan. Dalam turnamen, guru akan membagi ke dalam meja-meja turnamen yang diwakilkan oleh satu orang dalam setiap kelompok. Meja-meja turnamen akan dikelompokkan secara heterogen (Damayanti \& Apriyanto, 2017, p. 242).

5. Reward atau Penghargaan. Reward atau penghargaan merupakan sebuah apresiasi yang diberikan guru kepada kelompok yang telah mengumpulkan skor terbanyak atau tertinggi. Reward yang diberikan guru dapat berupa pujian, tanggung jawab dalam memimpin kelas, maupun hadiah. Tujuan diberikan reward agar siswa lebih termotivasi dalam belajar dan mengikuti setiap pembelajaran.

\section{Hasil}

Berdasarkan hasil data analisis koefisien korelasi dengan SPSS diperoleh hasil bahwa variabel teams games tournament $(\mathrm{X})$ berpengaruh terhadap variabel motivasi intrinsik $\left(\mathrm{Y}^{1}\right)$ siswa kelas VIIA SMPN 1 Simbuang. Dari tabel data koefisien korelasi 0,671 mencapai koefisien yang signifikan. Berdasarkan hasil data koefisien korelasi dengan SPSS diperoleh hasil bahwa variabel $X$ (teams games tournament) memiliki pengaruh terhadap variabel $\mathrm{Y}^{2}$ (motivasi ekstrinsik). Dari tabel data koefisien korelasi 0,479 mencapai koefisien yang signifikan.

Tabel 2. Koefisien Korelasi Variabel X dan Variabel $Y^{1}$

\begin{tabular}{llrr}
\hline & & TGT & Motivasi Intrinsik \\
\hline TGT & Pearson Correlation & 1 & $.671^{* *}$ \\
& Sig. (2-tailed) & & .001 \\
& $\mathrm{~N}$ & 20 & 20 \\
\hline Motivasi Intrinsik & Pearson Correlation & $.671^{* *}$ & 1 \\
& Sig. (2-tailed) & .001 & 20 \\
& $\mathrm{~N}$ & 20 & \\
\hline
\end{tabular}

**.Correlation is significant at the 0.01 level (2-tailed)

Dari hasil analisis didapatkan koefisien korelasi 0,671 dengan P-value 0,001 . Untuk menentukan apakah koefisien korelasi tersebut signifikan atau tidak, perlu dibandingkan dengan $r$ tabel. Jika $r$ hitung lebih besar daripada $r$ tabel, koefisien korelasi dinyatakan signifikan. Jika $r$ hitung lebih kecil daripada $r$ tabel, koefisien korelasi dinyatakan tidak signifikan. Dengan jumlah data sebanyak 20 responden, di dapatkan $r$ tabel pada $\alpha=0,05$ sebesar 0,423 . Hal itu menunjukkan 


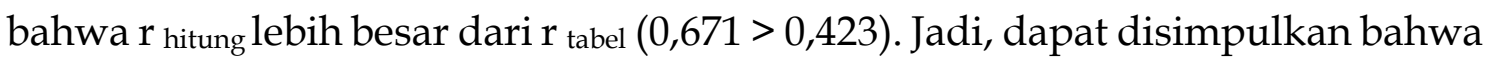
koefisien korelasi sebesar 0,671 adalah signifikan. Melihat besarnya koefisien korelasi tersebut, dapat dilihat bahwa hubungan antara TGT terhadap motivasi intrinsik tinggi atau kuat. Jadi, model pembelajaran kooperatif tipe teams games tournament dapat digunakan untuk memberikan motivasi intrinsik siswa.

Tabel 3. Koefisien Korelasi Variabel X dan Variabel $Y^{2}$

\begin{tabular}{llrr}
\hline & & TGT & \multicolumn{2}{r}{ Motivasi Ekstrinsik } \\
\hline TGT & Pearson Correlation & 1 & $.479^{*}$ \\
& Sig. (2-tailed) & & .033 \\
& $\mathrm{~N}$ & 20 & 20 \\
\hline Motivasi Ekstrinsik & Pearson Correlation & $.479^{*}$ & 1 \\
& Sig. (2-tailed) & .033 & 20 \\
& $\mathrm{~N}$ & 20 & \\
\hline
\end{tabular}

*.Correlation is significant at the 0.05 level (2-tailed)

Dari hasil analisis didapatkan koefisien korelasi 0,479 dengan P-value 0,033 . Untuk menentukan apakah koefisien korelasi tersebut signifikan atau tidak, perlu dibandingkan dengan $r$ tabel. Jika $r$ hitung lebih besar daripada $r$ tabel, koefisien korelasi dinyatakan signifikan. Jika $r$ hitung lebih kecil daripada $r$ tabel, koefisien korelasi dinyatakan tidak signifikan. Dengan jumlah data sebanyak 20 responden, di dapatkan $r$ tabel pada $\alpha=0,05$ sebesar 0,423 . Hal itu menunjukkan bahwa $r$ hitung lebih besar dari $r$ tabel $(0,479>0,423)$. Jadi, dapat disimpulkan bahwa koefisien korelasi sebesar 0,479 adalah signifikan. Melihat besarnya koefisien korelasi tersebut, dapat dilihat bahwa hubungan antara TGT terhadap motivasi ekstrinsik sedang atau cukup. Jadi, model pembelajaran kooperatif tipe teams games tournament dapat digunakan untuk memberikan motivasi ekstrinsik siswa.

\section{Pembahasan}

Pertama, berdasarkan hasil analisis data dengan menggunakan rumus rating skala, hasil data yang diperoleh pada variabel $X$ (teams games tournament) mencapai data hingga 1.695 dengan rating skala mencapai $84,75 \%$ yang berada pada interval setuju dan sangat setuju. Hal ini berarti variabel $X$ berada pada skala baik.

Kedua, berdasarkan analisis data variabel $\mathrm{Y}^{1}$ (motivasi intrinsik) mencapai skor 1.778 dengan rating skala mencapai $88,9 \%$ yang berada pada 
interval setuju dan sangat setuju. Hal ini berarti variabel $\mathrm{Y}^{1}$ berada pada skala baik dan menuju sangat baik.

Ketiga, berdasarkan analisis data variabel $\mathrm{Y}^{2}$ (motivasi ekstrinsik) memperoleh skor 1.657 dengan rating skala memperoleh skor 92,0\% yang menunjukkan pada interval setuju dan menuju interval sangat setuju.

Keempat, berdasarkan hasil data analisis koefisien korelasi dengan SPSS diperoleh hasil bahwa variabel Teams Games Tournament (X) berpengaruh terhadap variabel motivasi intrinsik $\left(\mathrm{Y}^{1}\right)$ siswa kelas VIIA SMPN 1 Simbuang. Dari tabel data koefisien korelasi 0,671 mencapai koefisien yang signifikan. Jadi, indikator pada variabel X (Teams Games Tournament) dan indikator $\mathrm{Y}^{1}$ (motivasi intrinsik) penulis menyimpulkan bahwa model pembelajaran kooperatif tipe Teams Games Tournament dapat diterapkan untuk memberikan motivasi belajar dari dalam diri siswa kelas VIIA SMPN 1 Simbuang pada pelajaran Pendidikan Agama Kristen.

Kelima, berdasarkan hasil data koefisien korelasi dengan SPSS diperoleh hasil bahwa variabel X (Teams Games Tournament) memiliki pengaruh terhadap variabel $\mathrm{Y}^{2}$ (motivasi ekstrinsik). Dari tabel data koefisien korelasi 0,479 mencapai koefisien yang signifikan. Jadi, indikator pada variabel X (Teams Games Tournament) terhadap indikator pada variabel $\mathrm{Y}^{2}$ (motivasi ekstrinsik) penulis menyimpulkan bahwa model pembelajaran kooperatif tipe Teams Games Tournament dapat diterapkan untuk memberikan motivasi belajar dari luar diri siswa kelas VIIA SMPN 1 Simbuang pada mata pelajaran Pendidikan Agama Kristen serta karena mempunyai pengaruh sedang atau cukup.

Berdasarkan analisis pembahasan menunjukkan bahwa pengaruh model pembelajaran TGT terhadap motivasi instrinsik lebih signifikan daripada motivasi ekstrinsik. Dengan demikian, model pembelajaran TGT dapat meningkatkan motivasi diri sendiri dibandingkan motivasi dari luar diri sendiri. Siswa kelas SMP 1 Simbuang menunjukkan memiliki motibasi instrinsik yang baik melalui penerapan model pembelajaran TGT. Beberapa penelitian penerapan model pembelajaran terbukti dapat meningkatkan motivasi dan hasil belajar (Sulfemi, 2019; Sulfemi \& Yuliana, 2019; Weismann, 2013). Penerapan model pembelajaran TGT dapat meningkatkan motivasi belajar yang memberikan pengaruh hasil belajar (Hikmah, Anwar, \& Hamid, 2018; Sulistyo, 2016). Secara khusus penelitian ini mengkaji komponen model pembelajaran TGT terhadap motivasi belajar (instrinsik dan ekstrinsik). 


\section{Kesimpulan}

Kesimpulan dari penelitian ini adalah: Pertama, model pembelajaran kooperatif tipe Teams Games Tournament merupakan salah satu model pembelajaran yang dapat digunakan saat mengajar agar tidak monoton dengan membentuk kelompok-kelompok secara heterogen guna membangun kerjasama, kejujuran, keberanian, tanggung jawab, dan keaktifan setiap anggota yang dilakukan dalam bentuk permainan akademik. Variabel X (teams games tournament) memiliki lima indikator yaitu presentasi kelas, membentuk kelompok, permainan akademik, turnamen, dan reward/penghargaan. Kedua, motivasi intrinsik adalah suatu kegiatan belajar yang didorong secara mutlak dari dalam diri dan dilakukan secara terus menerus sehingga memperoleh hasil belajar yang dapat menambah pengetahuan seseorang. Motivasi ekstrinsik sendiri merupakan suatu acuan penguatan dan dorongan yang diberikan dari luar diri seseorang dalam melakukan aktivitas belajar sehingga mencapai suatu tujuan. Ketiga, berdasarkan hasil data analisis koefisien korelasi dengan SPSS diperoleh hasil bahwa variabel teams games tournament $(X)$ terhadap motivasi intrinsik $\left(\mathrm{Y}^{1}\right)$ siswa kelas VIIA SMPN 1 Simbuang pada mata pelajaran Pendidikan Agama Kristen mencapai koefisien yang signifikan yaitu 0,671 yang berarti mempunyai hubungan yang kuat atau tinggi. Keempat, berdasarkan hasil data koefisien korelasi dengan SPSS diperoleh hasil bahwa variabel $X$ (teams games tournament) terhadap motivasi ekstrinsik $\left(\mathrm{Y}^{2}\right)$ siswa kelas VIIA SMPN 1 Simbuang pada mata pelajaran Pendidikan Agama Kristen mencapai koefisien yang signifikan pada skala 0,479, yang artinya berpengaruh sedang atau cukup. Berdasarkan hasil analisis data didapatkan bahwa model pembelajaran tipe teams games tournament (TGT) mempunyai pengaruh yang signifikan terhadap motivasi intrinsik dan motivasi ekstrinsik. Alasannya karena $r$ hitung lebih besar dari pada $r$ tabel.

\section{Rujukan}

Anggraeni, V., \& Wasitohadi, W. (2014). Upaya Meningkatkan Keaktifan Dan Hasil Belajar Matematika Siswa Kelas 5 Melalui Model Pembelajaran Kooperatif Tipe Teams Games Tournament (TGT) Di Sekolah Dasar Virgo Maria 1 Ambarawa Semester II Tahun Pelajaran 2013 2014. Satya Widya, 30(2), 121-136. https:/ / doi.org/10.24246/j.sw.2014.v30.i2.p121-136

Astriana, M., Murdani, E., \& Mariyam, M. (2017). Penerapan Model

Pembelajaran Kooperatif Tipe Teams Games Tournament Untuk 
Meningkatkan Kemampuan Pemahaman Konsep Matematis Siswa Pada Materi Operasi Bilangan Pecahan. JPMI (Jurnal Pendidikan Matematika Indonesia), 2(1), 117. https:// doi.org/10.26737/jpmi.v2i1.206

Bahri, A. S., Badawi, B., Hasan, M., Arifudin, O., Darmawan, I. P. A., Fitriana, F., ... Irwanto, I. (2021). PENGANTAR PENELITIAN PENDIDIKAN (Sebuah Tinjauan Teori dan Praktis) (N. S. Wahyuni, ed.). Bandung: Widina Bhakti Persada Bandung. https:// doi.org/10.0/CSS/ ALL.CSS

Damayanti, S., \& Apriyanto, M. T. (2017). Pengaruh Model Pembelajaran Kooperatif Tipe Teams Games Tournament Terhadap Hasil Belajar Matematika. JKPM (Jurnal Kajian Pendidikan Matematika), 2(2), 235-244. https:/ / doi.org/10.30998/jkpm.v2i2.2497

Edison, F. T. (2017). 52 Metode Mengajar: Mengangkat Harkat dan Martabat Pendidikan Menjadi Berwibawa dan Terhormat. Bandung: Kalam Hidup.

Hikmah, M., Anwar, Y., \& Hamid, R. (2018). Penerapan Model Pembelajaran Team Games Tournament (TGT) Terhadap Motivasi Dan Hasil Belajar Peserta Didik Pada Materi Dunia Hewan Kelas X Di SMA Unggul Negeri 8 Palembang. Jurnal Pembelajaran Biologi: Kajian Biologi Dan Pembelajarannya, 5(1), 46-55. https:/ / doi.org/10.36706/FPBIO.V5I1.7049

Ismawati, N., \& Hindarto, N. (2011). Penerapan Model Pembelajaran Kooperatif

Dengan Pendekatan Struktural Two Stay Two Stray Untuk Meningkatkan Hasil Belajar Siswa Kelas X SMA. Jurnal Pendidikan Fisika Indonesia, 7(1), 3841. https://doi.org/10.15294/jpfi.v7i1.1067

Jankawatu. (1997). Penerapan Metode Kuantitatif Dalam Penelitian Gerejawi. Jakarta: Departemen Agama RI.

Sholikah, L. M., \& Buditjahjanto, I. G. P. A. (2013). Pengaruh Permainan Bingo Dalam Model Pembelajaran Kooperatif Tipe NHT Terhadap Hasil Belajar Siswa Pada Standar Kompetensi Menerapkan Dasar-Dasar Teknik Digital Di SMKN 1 Jetis Mojokerto. Jurnal Pendidikan Teknik Elektro, 2(2), 707-714. Retrieved from

https://jurnalmahasiswa.unesa.ac.id/index.php/17/article/view/3530

Siregar, S. (2017). Metode Pemilihan Kuantitatif: Dilengkapi Dengan Perbandingan Perhitungan Manual \& SPSS. Jakarta: Prenada Media.

Sugiyono. (2012). Metode Penelitian Kuantitatif, Kualitatif dan RED. Bandung: Penerbit Alfabeta Bandung.

Sulfemi, W. B. (2019). Model Pembelajaran Kooperatif Mind Mapping Berbantu Audio Visual Dalam Meningkatkan Minat, Motivasi Dan Hasil Belajar IPS. 
Jurnal PIPSI (Jurnal Pendidikan IPS Indonesia), 4(1), 13-19. https:// doi.org/10.26737/jpipsi.v4i1.1204

Sulfemi, W. B., \& Yuliana, D. (2019). Penerapan Model Pembelajaran Discovery Learning Meningkatkan Motivasi Dan Hasil Belajar Pendidikan Kewarganegaraan. Jurnal Rontal Keilmuan Pancasila Dan Kewarganegaraan, 5(1), 17-30. https:/ / doi.org/10.29100/JR.V5I1.1021

Sulistyo, I. (2016). Peningkatan Motivasi Belajar Dengan Menerapkan Model Pembelajaran Kooperatif TGT Pada Pelajaran PKN. Jurnal Studi Sosial / Journal of Social Studies, 4(1), 19. Retrieved from http://jurnal.fkip.unila.ac.id/index.php/JSS/article/view/10963

Sumantri, M. S. (2016). Teori dan Praktik Di Tingkat Pendidikan Dasar. Jakarta: Rajawali Pers.

Tiya, K. (2017). Penerapan Model Pembelajaran Kooperatif Tipe Teams Games Tournament (TGT) dalam Upaya Meningkatkan Hasil Belajar Matematika Siswa SMPN. Jurnal Pendidikan Matematika, 4(2), 178-191. https:// doi.org/10.36709/jpm.v4i2.2032

Trianto. (2012). Mendesain Model Pembelajaran Inovatif-Progresif: Konsep, Landasan, Dan Implementasinya Pada Kurikulum Tingkat Satuan Pendidikan. Jakarta: Kencana.

Weismann, I. T. J. (2013). Analisis Pengaruh Gaya Kepemimpinan Dosen Terhadap Motivasi Belajar Mahasiswa Sekolah Tinggi Theologia Jaffray Makassar. Jurnal Jaffray, 11(1), 67-86. https:/ / doi.org/10.25278/jj71.v11i1.75 Widiyanto, M. A. (2014). Statistika untuk Penelitian Bidang Teologi, Pendidikan Agama Kristen, dan Pelayanan Gereja. Bandung: Kalam Hidup.

Wijaya, H. (2018). Analisis Data Kualitatif Ilmu Pendidikan Teologi. In Populasi dan Sampel. Makassar: Sekolah Tinggi Filsafat Theologia Jaffray Makassar. 